a plan for relieving varix, and this consisted in what might be called subcutaneous vene. gection; the proceeding consisted in the passage of a convex bistoury under the vein, and cutting towards the skin without dividing it; this was to be followed up by the application of compresses and bandages. Mr. Mayo had recommended the application of caustic potash over the varix, but in this proceeding the vein was apt to become involved in the slough and hrmorrhage occasioned; when this did occur, if the patient was erect the blood flowed out with amazing rapidity, and in great volume, though not with force; it was, however, easily stopped by pressure and friction. He (Mr. L.) had followed, for a long period, the mode recommeuded by $\mathrm{Mr}$. Mayo; it was generally successful, and only in one instance did bleeding occur. A plan, had, however, lately been proposed by M. Telpeau, and this consisted in passing pins under the vessel, and applying over them a twisted thread; these pins made their escape by ulceration, or were not removed until this occurred. This plan, modified and improved, they had seen often practised here; the object aimed at, was to produce coagulation and obliteration of the vessel at one or more points. For this purpose two long harelip pins were passed ander the vessel, leaving about half an iuch of it interposed; the threads were then applied. It often was necessary to obliterate the canal at various points, as when the lesser saphena was also implicated. The part of the vein operated upon soon became firm and permanently closed; the blood coagulating and the coats becoming thickened; in some cases eveu in twelre hours this happened, but more frequently from twenty-four to forty-eight hours'were required for the completion of the process, and the pins could safely be taken out at the expiration of a few days, a drop or two of blood only coming away. Mr. Blake had found in some experiments that the blood in the jugular vein of a dog, in whom he had adopted this proceeding, became coagulated in the space of sixteen hours. He (Mr. L.) was, however, afraid that such a short time could not be safely taken as a standard in operations upon the human frame, and on reins in a dilated and diseased state. The operation produced no suffering.

\section{DISLOCATION OF THE HUMERUS ON THE}

DORSUM SCAPULRE.

By J.C. Bellamy, MI.R.C.S., Yealmpton.

William Smale, aged about 50, whilst hunting, was precipitated to the ground, by his horse falling nuder hirs, and was then drawn a considerable way by the animal, his foot still hanging in the stirrup; he wat conscious of some sudden slip in his sboul. der at the moment of the fall. Finding that he suffered severe pain, and was greatly bruised, I bled him on his first arrival home, when he seemed greatly relieved, but being cardle-light I deferred operating on his dislocated arm till the morrow. The symptoms of this luxation, of which I took note, were as follow:-Slight œdema of the whole arm, numbness, and a sensation even as if the member were deficient; pain on the in. side of the arm, about the situation of the nerve; elbow slightly turned out; the patient obliged, through pain in the shoulder, to support the arm gently, and with the greatest care, yet the extremity could be placed close to the side, and carried ont to horizontality, without pain, but forward and backward motion caused great suffering referred to the head of the humerns, which appeared under a thin covering of muscle (infraspinatus) behind and below the acromion, and quite posterior to the anterior costa, or thickened margin of the scapula. This position made the joint seem, as it were, particularly broad in the anteroposterior direction, or gave the joint a double aspect, as if there were two heads of the os brachii present, or a twofold volume of the deltoid; on accurate measurement the two arms were found of equal length. The other symptom deserves especial notice, and has not been recorded by any author; from the course taken by the shaft of the bone to its unnatural location, it necessarily left the front margin of the deltoid in its due course to the centre of the shaft, so that an obtuse angle appeared in the arm, formed below by the inferior por. tion of the shaft, and above by the descend. ing anterior margin of the deltoid; and, again, an extraordinary width and fatness of the whole upper part of the outside of the limb, was naturally produced by the poste. rior course now assumed by the humerus.

In the reduction I determined to pursue the mode recommended by Mr. Coley. Haring rendered the scapula a fixed point, by the long towel encompassing that bone, and having the arm passed through an aperture in its centre, and being held at its two ends by a strong assistant on the opposite side of the patient, I raised the arm, without great pain, above the horizontal position, and turned it so as to give the head of the humerus an insinuating movement over or on the costa scapulæ. I then directed an as. sistant to make extension directly outwards, and, finally, somewhat downwards. The bone almost immediately returned, and two crepitations were distinctly heard, one, perhaps, occasioned by the passage of the bone orer the costa, and the other when it finally sunk into its natural cavity. The patient remarked on the instantaneous relief which the reduction afforded him. 